Editorial

\title{
Method as Border: Tuning in to the Cacophony of Academic Backstages of Migration, Mobility and Border Studies
}

\author{
Kolar Aparna ${ }^{1, *}$, Joris Schapendonk ${ }^{1}$ and Cesar Merlín-Escorza ${ }^{1,2}$ \\ ${ }^{1}$ Geography, Planning, Environment Department, Institute for Management Research, Radboud University, 6525 Nijmegen, \\ The Netherlands; E-Mail: k.kolaraparna@fm.ru.nl (K.A.), j.schapendonk@fm.ru.nl (J.S.), \\ c.merlinescorza@fm.ru.nl (C.M.-E.) \\ ${ }^{2}$ Anthropology and Development Studies Department, Radboud University, 6525 Nijmegen, The Netherlands \\ * Corresponding author
}

Submitted: 12 October 2020 | Published: 19 November 2020

\begin{abstract}
This thematic issue is a collection of articles reflecting on methods as border devices of hierarchical inclusion spanning migration, mobility and border studies. It maps some key concerns and responses emerging from what we call academic backstages of migration, mobility and border research by younger academics. These concerns are around (dis)entangling positions beyond Us/Them (i.e. researcher/researched), delinking from the spectacle of migration and deviating from the categories of migration apparatuses. While these concerns are not new in themselves the articles however situate these broader concerns shaping migration, mobility and border studies within specific contexts, dilemmas, choices, doubts, tactics and unresolved paradoxes of doing fieldwork. The aim of this thematic issue is not to prescribe "best methods" but in fact to make space for un-masking practices of methods as unfinished processes that are politically and ethically charged, while nevertheless shedding light in (re)new(ed) directions urgent for migration, mobility and border studies. Such an ambition is inevitably partial and situated, rather than comprehensive and all-encompassing. The majority of the contributions then enact and suggest different modes of reflexivity, ranging from reflexive inversion, critical complicity, collective self-inquiry, and reflexive ethnography of emotions, while other contributions elaborate shifts in research questions and processes based on failures, and doubts emerging during fieldwork. We invite the readers to then read the contributions against one another as a practice of attuning to what we call a 'cacophony of academic backstages,' or in other words, to the ways in which methods are never settled while calling attention to the politics of knowledge production unfolding in everyday fieldwork practices.
\end{abstract}

\section{Keywords}

backstage; borders; methods; migration; mobility; politics of knowledge, reflexivity

\section{Issue}

This editorial is part of the issue "Method as Border: Articulating 'Inclusion/Exclusion' as an Academic Concern in Migration and Border Research in Europe" edited by Kolar Aparna (Radboud University, The Netherlands), Joris Schapendonk (Radboud University, The Netherlands) and Cesar Merlín-Escorza (Radboud University, The Netherlands).

(C) 2020 by the authors; licensee Cogitatio (Lisbon, Portugal). This article is licensed under a Creative Commons Attribution 4.0 International License (CC BY).

\section{Introduction: Borders, Methods and the Academic Backstage}

In their book, Border as Method, Mezzadra and Neilson $(2013$, p. 7) argue that "borders are devices of inclusion that select and filter people and different forms of circulation in ways no less violent than those deployed in exclusionary measures." In this thematic issue we are interested in how such devices entangle with the methods employed by researchers engaged in migration, mobility and border studies. The concept of 'method as border,' then, serves as a lens to bring attention to the shifting positionalities emerging in relation to the shifting mutations of migration and border regimes ques- 
tioning the very foundations and assumptions of conventional disciplinary methods underpinning research. The foundation for this thematic issue emerged from intensive discussions at the Nijmegen Centre of Border Research, where all three authors of this editorial are based. Speaking from different positionalities-in terms of the personal experiences we have, academic positions we hold, the debates we participate in-we have increasingly felt the need to actively create spaces for collective conversations that are often uncomfortable, as we question our own methods and academic practices. We do so in an academic context that produces its own anxieties based on ranking systems and competition (Berg, Huijbens, \& Larsen, 2016), where such a collective space for doubt and discomfort is shrinking. But this also needs to be seen in light of the anxieties emerging from doing migration, mobility and border research in Europe and the privileges and blind spots this entails. This thematic issue began with a collective question: How do (younger) academics make sense of the financialization, over-politicization and hyper-relevance of migration, mobility and border research in their choice of methods?

With this thematic issue we aim to create a critical space for reflection on our positions and methods. We call this space the academic backstage for two reasons. First, it is a space from where we articulate some of the invisible labour, hidden choices of location, objects of inquiry, scales, alongside ambivalences and shifts behind our academic positions and performances as migration mobility and border researchers situated in a wider sociopolitical climate. Like artists look at themselves in the mirror as they wait backstage, we invite migration, mobility and border scholars to do the same; to stand still and critically re-look, to (dis/re)engage, or deviate from the grant proposals, dominant academic practices, and value positions one is trained in or expected to demonstrate expertise on, especially in a global context of rat-racing for grants and pumping out publications.

As stated by Grönfors (1982), this is (still) needed:

By being scientific the social scientist has been able to divert attention away from the real person$\mathrm{him} /$ herself-towards an esoteric and invisible community of scientists from which his or her lead is taken, but which, like God, can never be called upon to justify its position.

While researchers are being called upon to clarify their outcomes as part of funding regimes and promotional structures of university systems, we are held less accountable to our own messy role in the messy processes of re-search-ing in a field that is itself highly politicized. Here, indeed, shifting positions emerging in relation to encounters, or processes of being called upon to justify one's position from non-academic actors, or one's own moral dilemmas from intuitive and ongoing questions of learning and unlearning one's privileges and blind spots along the way, are urgent. Only when we move away from the spotlight and god-like status are we able to ask ourselves fundamental questions: Where do we put our analytical gaze? With whom do we speak? Whose knowledges should be central? Where do we go, and for what reasons?

Secondly, this backstage allows us to revisit certain methods and normalised 'objects of inquiry' as (potentially) feeding into border regimes and migration apparatuses, regardless of consciously choosing to do so or not, that we believe needs critical reflection. Here we invite early stage academics to share tactics they adopt in shifting the gaze away from the spectacle and adopting reflexive methods to avoid reproducing the design principles of migration apparatuses and border regimes in one's own research designs.

With these two dimensions (questions regarding one's position in a wider socio-political field of struggles over what knowledges come to matter and why, and the direct links between academic work and border devices) we seek to discuss what is included/excluded and visible/invisible in and through our everyday academic work, with the purpose of starting a collective conversation; to learn from each other's doubts, questions, struggles, discomforts and failures, rather than solely from successes and 'products of ideas.' This introduction elaborates on the two dimensions of the academic backstage. The contributions to this issue are discussed along the way.

\section{Academic Backstage I: (Dis)entangling Positions beyond Us/Them}

First, behind every academic performance-behind every smooth argument, funded proposal, methodological design-there are uncertainties, nerves and preparations that we seldom make visible in our frontstage performances. The first backstage reflection this thematic issue provides speaks to these personal positions. To articulate this, we outline our own differential positions to start these collective conversations. From his stable academic position (assistant professorship, longterm contract), author Joris Schapendonk started to unpack his personal ambivalences regarding his work of the last decade that concentrated on migrant trajectories. While his methods of following trajectories can be regarded an academic success (as it resonates in others' work), he increasingly feels uncomfortable with this approach too and/or how it is framed by colleagues. Despite its methodological strength-it helps to unfreeze migrant positionality and seeks to contribute to the demigranticization of migration studies (Dahinden, 2016)this approach risks to reinforce the over-politicized view on migration processes, rather than creating an intellectual escape route.

Author Kolar Aparna's recently defended PhD thesis emerged from uncomfortable conversations she had with many people waiting for their citizenship-papers across EU states (Aparna, 2020). These conversations 
were uncomfortable because it was regarding her role in their collective struggles for intellectual valuation in asylum centres and camps and right to education, among others. This is related to her emerging discomfort with academic practices that fragment-fragment theoretical abstraction from lived, embodied struggles and stories; fragment researcher from researched; fragment 'university' from 'the field.' She chose to move away from speaking about or with 'asylum-seekers,' or borders that 'they' face, to speaking from asylum as a condition of enacting a politics of citizenship in everyday relations, produced at the intersections of academic/-refugee practices. This indeed opened up spontaneously chosen methods to articulate related conditions of borders from different positionalities of enacting asylum. These ranged from collective auto-ethnography, montaging, focus groups, workshops for developing curricula etc, in relation to the purpose of keeping classroom doors, syllabus and publication practices open for critique, co-production and co-authorship. The topics emerged along various directions urgent for collective struggles of opening up the university to communities otherwise excluded, right to education, and intellectual valuation in camps and asylum centres. However, the unequal income between her and some of her co-authors, not hired by universities and not recognized as citizens in Europe, continues to reinforce the unequal conditions of knowledge exchange. Also, the equally important struggles to build a curriculum that speaks to diverse subject positions across imperial divides remains an uphill struggle, given her own precarious academic position as a post-doc with a temporary contract.

Although already aware of many of the contradictions of the creation, legitimation and practice of scientific knowledge, author Cesar E. Merlín-Escorza's recent engagement in ethnographic research and academic performance related to migrant and refuged individuals have motivated him to question the purpose and means of this kind of work. Now in his second year as a PhD candidate at the geography and anthropology departments, he has come to scrutinize research and teaching practices departing from collective experiences and the latest developments in his research project, in particular in relation to the COVID-19 global pandemic. In such a context, the uncertainty of (not) being able to travel outside Europe to work in the field, helped him question his choices regarding the setting and groups of individuals in his study, and the relation between these and his position in the world. In conversation with other (young) researchers located at universities in the Global South and North, whilst trying to build more critical research designs, he has found in decolonial streams of thought and practice, the possibilities for 'doing a job' that gives priority to wealth redistribution and social justice.

With our focus on the backstage of academia, we want to make these concerns, shifts and (self)doubts that cross-cut academic positions insightful, in order to unpack some of the emotional labour, power asymme- tries and political dilemmas in the process of 'staging' our research. In this issue, Lems (2020), for instance, confronts the dominant concerns of the ethnographic research traditions she is trained in, of "empathy," and of "lending marginalized people a voice" (p. 116). Lems reflects on encounters with her research participants, in this case a group of 'refugee youth' in Switzerland, who challenged her assumptions of 'participation' (in using methods of participatory observation) by refusing to tell their stories, while shifting her research gaze to examine opaque yet violent acts of boundary drawing in everyday relations of refugee support and care.

Wajsberg (2020), rather than driven by empathy in ethnographic research, centres on the emotion of fatigue as an analytical object and a methodological tool to engage in reflexive ethnography with the purpose of investigating the uneven power geometries of research relations in what she calls "Europe's migration control field" (p. 126). By taking the reader through different scenes that entangle research fatigue, compassion fatigue and racial battle fatigue, she draws our attention to the uneven emotional geographies of migration control that researchers move in, and also in turn shape.

\section{Academic Backstage II: Delinking from the 'Spectacle,' Deviating from Categories of 'Migration Apparatuses'}

All the contributions to this thematic issue explicitly incorporate the politics of relationality between methods as devices of hierarchical inclusion across research and bordering practices. In so doing, this thematic issue discusses a range of doings that all speak to the way methods become highly political artefacts and how research designs reflect a wider politics of knowledge production (Aparna, 2020; Chimni, 1998). We do not depart from empirical projects that share a particular focus-be it the migrant, the border guard, the border regime-but invite reflections across subject positions, objects of inquiry and methodological traditions.

In the field of migration and border studies, it is convincingly argued that much of the way questions are raised, project objectives phrased, research subjects selected and empirical insights collected, is closely entangled with the quest of migration regimes, and most notably nation-states, to manage migration better. Dahinden (2016), for instance, outlines how 'migration' and 'migration related categories' are actually artefacts of migration apparatuses. When researchers uncritically follow these labels with their research questions, they contribute to a discursive normalization of difference (see also Giglioli, Hawthorne, \& Tiberio, 2017). Hence, Dahinden (2016) urges researchers to disentangle their concepts and categories from nation-state agendas, and instead work more closely with the study of social processes at large related to the topic at hand.

One of the escape routes to break with the normalized discourse of powerful regimes is to use a mobili- 
ty framework instead of a migration framework. In this sense, as argued by Davidson (2020) and Schapendonk, Bolay, and Dahinden (2020), mobility studies can be seen as a radical project for breaking with the sedentary tradition of social science and pre-fixed categories of difference often reproduced in migration studies, such as migrant versus citizen. This means that mobility is seen as a fundamental aspect of life, and from this starting point we may consider approaches of what it means to be mobile, and how this is defined in various contexts. With the mobilities approach, we can analyse when, where, how and whose mobilities and stasis is denied, exceptionalized and migranticized, and through which practices this occurs (Schapendonk, 2020). Rather than taking migrancy as a marker of difference (Schapendonk et al., 2020), or taking terms like citizen/migrant as fixed, static categories, this approach invites is to critically reflect and redefine our terms and categories of analysis. However, mobilities studies have become a frontstage in themselves, a 'trend'/'turn,' bypassing some of the politics and practices behind the methods applied.

The contribution by Boas, Schapendonk, Blondin, and Pas (2020) to this thematic issue is a collective reflection on mobile methods. They reflect on the paradoxes of deviating from the sedentary research designs driving mobility studies, the messiness in choices in doing so and the dilemmas around articulating and transcending difference between researchers and participants through mobile methodologies. Reflections on fieldwork encounters that destabilize the researcher's gaze seeking 'spectacular sites of crossings' and 'mundaneness in daily pathways,' lays bare the borderline-imaginaries continuing to haunt mobility frames. It is also reflected in this contribution that the urge to 'move with' actors pre-identified as, for instance, 'environmental migrants' or 'pastoralists,' hides more than it reveals regarding the temporal dimensions, complex connections and fragmented forms of mobilities in relation to gradual environmental changes. Centring one's own embodied experiences of mobility and reflecting on one's motility (mobility potential) in 'the field,' rather than solely the 'other's,' is reflected as having potential to know uneven geographies of mobility through kinaesthetic and sensual dimensions. The collective reflections in the article leave us with some fundamental unresolved issues haunting methods based on mobile ontologies of social phenomenon, namely: Why capture the Other's mobility? Who writes about whose mobility? Which frame is given to someone's mobility and why do so? What does consent mean in a context of shifting conditions and precarity of the 'researched'? Yet the authors urge for a focus on the importance of mobile methodologies in analysing practices of mobility as shaping research relations and, therefore, also unequal relations of mobility and immobility otherwise hidden, rather than the elusive goal of representing 'the Other's' (im)mobility experiences.

Although this mobility approach seeks to address (in its own way) an ontology of separation (e.g.,
Naylor, Daigle, Zaragocin, Ramírez, \& Gilmartin, 2018), the extractive and exclusionary dynamics of migration research reproducing unequal research relations remains implicit. Bass, Cordova, and Teunissen (2020) reflect on how discriminatory practices of so-called 'migration scholars' can be explained as traces of the "imperial eyes" through which academia legitimizes such dynamics. As early stage researchers they are influenced by scholars working with the autonomy of migration, liberation theory, critical perspectives of indigenous peoples/individuals and those working on the frontlines. From this mixed source of inspiration, Bass et al. (2020) invite us to question our methods and approaches by providing a set of tools which could be applied by researchers not only inside but also outside academic structures. Motivated by their shared affinities rather than disciplinary or methodological concerns, the authors find in the "collective process of self-inquiry" (Bass et al., 2020, p. 150), a path to delink from the individualistic tendency of academic work. By analysing the concomitance between their positionalities, privileges and the discriminatory practices developed at all times in the research process, they re-centre such analysis as core to migration research. Just as the invitation remains open, the complexity of such a challenge remains evident, for the achievement of a liberatory academic practice encompassing a diversity of ways-of-doing represents an ongoing struggle "towards the undercommons" (Bass et al., 2020, p. 154) as an unfinished project.

Such tools of collective self-inquiry are but one among others to avoid becoming non-reflexive systems designers. In this regard, attention to politics of location in research on EU borders is raised from two different angles. Behind the frontstage of bordering, such as camps and hotspots and detention sites, Pollozeck (2020) argues, is the 'elsewhere,' such as in databases of Eurodoc or headquarters of Frontex and Europol. With the physical camp Moria burnt down during the time of writing this introduction, Pollozeck's article remains witness to the camp's ongoing social life as a 'logistical set-up,' where data is generated and spread across state institutions. Bordering, it is argued, is most importantly a sociotechnical and socio-material phenomenon, from a praxeographic approach. However, rather than the assumed collaborative forms of knowledge production underpinning praxeographic mapping, disentangling the opaque institutional ecologies of migration and border control for making new associations, especially of the Moria hotspot, he argues, can enable forging new alliances and creating new collectives outside academia, such as those focusing on data protection and data monitoring.

Along similar lines, Kristensen (2020) urges us to rethink the complicity of researchers in reproducing the drama of the 'migration industry,' based on her research conducted among EU border enforcement officials. Rather than critical distance, she urges scholars to nurture the capacity of critical complicity. Such a practice, she argues, can unfold at three levels, namely 1 ) by 
assessing the locations of fieldwork and the ways they either mirror or distort dominant narratives about the borders of Europe, 2) probing into differences and similarities between objects of inquiry of interlocutor and researcher, and, finally, 3) re-routing the aim of ethnography as additions rather than evidence or revelations.

\section{Tuning-In to the Cacophony of Academic Backstages}

With this issue we thus address the way migration, mobilities and border research is itself part of a moving sociopolitical context that directs and affects our research questions, methods and practices. This also makes it hard to claim centre stage as academics in a field where knowledges are claimed by multiple actors, regimes and institutional practices. This thematic issue is a call to tune our senses collectively to the cacophony of voices emerging in the wings of 'academic backstages' in response to these politics of 'claiming' intellectual space in what Wajsberg (2020) calls "Europe's migration control field" (p. 126). The term cacophony is used because this inevitably implies discordant views, rather than singularly coherent voices flying the same flag of methods. It implies tuning our senses to cacophonic rhythms that, when rubbed against each other, or collide with each other, produce ripple effects beyond territorial camps of methods. This thematic issue itself is such a cacophonical rhythm-space. Such an evolving architecture of cacophonical backstages of academic practice demands a stubborn insistence on practices of sharing doubts, and acknowledging failures, complicities, and affinities. At the same time, it also implies being collectively accountable to acts of producing inequalities, similarities and difference, extraction and transformation, inclusion and exclusion, in ways that reject the self-confident individualised templates dictated by funding regimes and managerial tools governing academic thought.

The backstage space of this issue is, then, an invitation to the reader to tune-in to the cacophony emerging from the dizzying conversations towards the 'undercommons,' the dry vocabulary of praxeographic approaches, the shaky tones of fatigue, the sobering forms of unlearning and admitting privilege, bias and fallacies, and the meticulous layers of critical complicity, among all the many shades these writings and this collection of articles might induce in the reader.

We urge for a shaking up of the monotonal complacency in the academic fields of migration, mobility and border studies, which is full of writing ever more about borders, and/or migrants. More knowledge, more details, can lead to more closures and further oppression of the already oppressed (Khosravi, 2018). As a consequence of the researcher's ambition for new and creative knowledge, scientific methods and writing can expose the clandestine necessity of certain migration pathways and practices. By creating more knowledge or a better understanding regarding unauthorised mobilities within migration regimes, stakeholders of control and containment, namely State institutions or non-State actors (like organizations profiting from migrant bodies and lives), can better grasp the knowledges and practices developed by the ones dwelling and moving through the cracks of such regimes (Cabot, 2019). Instead, we urge for spaces that speak from positions that inevitably implicate the researcher whether one likes it or not and whether one is explicit about this or not, as part of the 'fields of inquiry.' In so doing, rather than constantly separating 'spaces of expertise' (i.e., the University) from the field where the 'grasping' is done or 'data collected' (Aparna, 2020; Glissant, 1997), we urge for re-centring the moments, events, encounters, failures, shifts and transformations that disrupt, re-engage, and re-articulate such relations from various angles. Such an academic backstage is, therefore, not a space to share our academic comforts, but rather to put our finger on our discomforts. It is not a space for new research questions, but a space to question the questions we raise. It is not a ground to learn new research techniques, but rather a ground to unlearn routines. It is not a space for applauding our academic successes, but rather a space to close the curtains of the frontstage and tuning in to the cacophony of academic backstages.

\section{References}

Aparna, K. (2020). Enacting asylum university: Politics of research encounters and (re)producing borders in asylum relations (Unpublished Doctoral dissertation). Radboud University, Nijmegen, The Netherlands.

Bass, M. J., Cordova, D., \& Teunissen, P. (2020). (Re)searching with imperial eyes: Collective selfinquiry as a tool for transformative migration studies. Social Inclusion, 8(4), 147-156.

Berg, L. D., Huijbens, E. H., \& Larsen, H. G. (2016). Producing anxiety in the neoliberal university. The Canadian Geographer/Le géographe Canadien, 60(2), 168-180.

Boas, I., Schapendonk, J., Blondin, S., \& Pas, A. (2020). Methods as moving ground: Reflections on the 'doings' of mobile methodologies. Social Inclusion, 8(4), 136-146.

Cabot, H. (2019). The business of anthropology and the European refugee regime. American Ethnologist, 46(3), 261-275.

Chimni, B. S. (1998). The geopolitics of refugee studies: A view from the South. Journal of Refugee Studies, 11(4), 350-374.

Dahinden, J. (2016). A plea for the 'de-migranticization' of research on migration and integration. Ethnic and Racial Studies, 39(13), 2207-2225.

Davidson, A. C. (2020). Radical mobilities. Progress in Human Geography. Advance online publication. https://doi.org/10.1177\%2F0309132519899472

Giglioli, I., Hawthorne, C., \& Tiberio, A. (2017). Introduction. Etnografia e ricerca qualitativa, 2017(3), 335-338. https://doi.org/10.3240/88709 
Glissant, É. (1997). Poetics of relation. Ann Arbor, MI: University of Michigan Press.

Grönfors, M. (1982). From scientific social science to responsible research: The lesson of the Finnish Gypsies. Acta Sociologica, 25(3), 249-257.

Khosravi, S. (2018). Afterword. Experiences and stories along the way. Geoforum. https://doi.org/10.1016/ j.geoforum.2018.05.021

Kristensen, M. P. (2020). EU border officials and critical analysis: The politics of location and ethnographic knowledge as addition. Social Inclusion, 8(4), 169-177.

Lems, A. (2020). Phenomenology of exclusion: Capturing the everyday thresholds of belonging. Social Inclusion, 8(4), 116-125.

Mezzadra, S., \& Neilson, B. (2013). Border as method, or the multiplication of labor. Durham, NC: Duke University Press.

Naylor, L., Daigle, M., Zaragocin, S., Ramírez, M. M.,
\& Gilmartin, M. (2018). Interventions: Bringing the decolonial to political geography. Political Geography, 66, 199-209.

Pollozeck, S. (2020). Mapping European border control: On small maps, reflexive inversion and interference. Social Inclusion, 8(4), 157-168.

Schapendonk, J. (2020). Finding ways through Eurospace: West African movers re-viewing Europe from the inside (Vol. 7). New York, NY: Berghahn Books.

Schapendonk, J., Bolay, M., \& Dahinden, J. (2020). The conceptual limits of the 'migration journey.' De-exceptionalising mobility in the context of West African trajectories. Journal of Ethnic and Migration Studies, 1-17. https://doi.org/10.1080/1369183X. 2020.1804191

Wajsberg, M. (2020). Following fatigue, feeling fatigue: A reflexive ethnography of emotion. Social Inclusion, 8(4), 126-135.

\section{About the Authors}

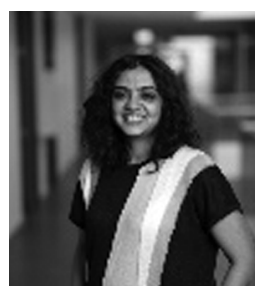

Kolar Aparna is a mother of a 4-year-old and has a background in Performing Arts and Human Geography. Based on collective action-research processes, her PhD thesis calls attention to the borders of academic practices that entangle with borders in everyday asylum support practices. She is currently working as Assistant Professor in the Human Geography department at Radboud University.

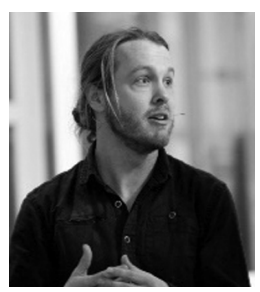

Joris Schapendonk is Assistant Professor at the Geography, Planning and Environment department of Radboud University and an active member of Nijmegen Centre for Border Research (NCBR). His research concentrates on $\mathrm{im} /$ mobility trajectories, borders and migration industries. His work is published in, among others, Annals of the Association of American Geographers (2014), Journal of Ethnic and Migration Studies (2018; 2020) and Geoforum (2018). His latest book, Finding Ways in Eurospace (2020), is published by Berghahn Books (https://www.berghahnbooks.com/ title/SchapendonkFinding)

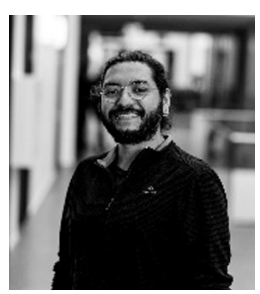

Cesar Merlín-Escorza was born in México Distrito Federal in 1985. At 21 he migrated to the United States and worked there for three years, learning from the experiences with/of "illegal" immigrant workers. At 24 he began studying Social Anthropology at UAM-Iztapalapa in México, researching about transnational identities. In 2017 he migrated to The Netherlands to do a master in anthropology at Radboud University and continued with the $\mathrm{PhD}$, researching about the discourses and performativities in sheltering practices. 